\title{
A hospital based study on the usage pattern of Child Health Development Record as an information source on infant and young child feeding
}

\author{
M N Danansuriya ${ }^{1}$, K Guruge ${ }^{2}$, R R K Wijewardena ${ }^{3}$ \\ Sri Lanka Journal of Child Health, 2013; 42(3): 133-138
}

\begin{abstract}
Objective: To assess the usage pattern of child health development record (CHDR) as an information source by the mothers of children aged 6-24 months admitted to a ward in Lady Ridgeway Hospital (LRH) and to assess their level of knowledge and practices on infant and young child feeding (IYCF).
\end{abstract}

Method: A cross-sectional study was conducted in a paediatric ward in LRH from $1^{\text {st }}$ February to $31^{\text {st }}$ August 2009 on mothers with children aged 6-24 months. Feeding patterns, maternal knowledge on messages given in CHDR and selected sociodemographic factors were examined using a pretested interviewer-administered questionnaire. Association of feeding practices and sociodemographic characteristics were analyzed using non parametric tests. Ethical approval was granted by the ethical review committee of LRH.

Results: Of the 300 mothers administered questionnaires 5 were excluded due to incomplete data. Of the 295 mothers included in study, $36 \%$ had passed GCE ordinary level. Of the children, $72 \%$ started complementary feeding after 6 months. Nearly $50 \%$ of children had satisfactory diet in terms of quality, quantity and frequency. Maternal IYCF knowledge was significantly associated with maternal educational level and reading of CHDR feeding instructions.

Conclusion: Mothers have an acceptable level of knowledge on IYCF and satisfactory level of usage of CHDR as an information source. Reading CHDR has a significant impact on higher maternal IYCF knowledge and better IYCF practices.

(Key words: Infant \& young child feeding; Child Health Developmental Record; maternal knowledge)

${ }^{1}$ Consultant Community Physician, Family Health Bureau, Ministry of Health, Colombo, ${ }^{2}$ Consultant Paediatrician, Colombo, ${ }^{3}$ Senior Registrar in Paediatrics, Colombo South Teaching Hospital

(Received on 30 August 2012: Accepted after revision on 19 October 2012)

\section{Introduction}

Child malnutrition remains a common problem in developing countries including Sri Lanka ${ }^{1}$. In many countries faulty complementary feeding practice is a major contributing factor to infant and young child malnutrition, growth failure, high morbidity and mortality ${ }^{1-3}$. Child rearing and caring practices vary according to socio-cultural background, maternal educational levels, poverty and many other factors ${ }^{4,5}$. Sri Lanka has adopted and started implementation of WHO/UNICEF global strategy on infant and young child feeding (IYCF) practices with the aim of promoting exclusive breastfeeding for 6 months and complementary feeding practices after 6 months ${ }^{5}$.

For Sri Lankan mothers, the main sources of information on IYCF are public health midwife, family members, friends and mass media. The child health programme implemented by the Ministry of Health is responsible for growth monitoring and promotion through the field health staff at grass root level. Every child born in Sri Lanka is given a Child Health Development Record (CHDR) at birth and it is used to record growth and development ${ }^{6}$. In addition, this booklet is used as an information source or education material for communicating knowledge to caregivers regarding child caring and rearing. However, in practice, it is observed that mothers are not optimally utilizing the information provided in CHDR to improve their child's growth and nutrition. Therefore, the present study was planned with the aim of assessing the knowledge of mothers with regard to IYCF information provided in the CHDR and to explore to what extent mothers are using the CHDR as an information source.

\section{Method}

A descriptive cross-sectional survey was carried out in a paediatric medical ward in the Lady Ridgeway Hospital (LRH) on mothers of children aged 6-24 months admitted from $1^{\text {st }}$ February to $31^{\text {st }}$ August 2009. The exclusion criteria were children with more than 3 hospital admissions, children with congenital anomalies or chronic diseases, children with mothers/caregivers who do not understand Sinhala or if the bystander is not the mother of the child. LRH is 
a tertiary care hospital to which patients with various socioeconomic and educational backgrounds are referred from all over the country. An interviewer administered questionnaire was used to collect data. The structured questionnaire was locally designed based on expert's comments, IYCF guidelines and CHDR. It was pretested and modified accordingly. The questionnaire was administered by two trained postgraduate trainees in paediatrics within two days of child's admission to the ward.

To obtain information on routine feeding pattern, a 24 hour dietary recall was done with regard to the day the child was last well. To get an idea about portion sizes, commonly available measures like tea cups, saucers and table spoons were used. Special attention was given to find out whether the mothers were able to read the feeding instructions of the CHDR and if they could not, the reasons. Level of knowledge on age appropriate feeding and myths regarding complementary feeding were examined. Regarding knowledge on IYCF, 15 closed questions were included and mothers were asked to respond as correct, incorrect and don't know. Each correct response was given one mark. Ethical clearance was obtained from the ethical review committee of LRH, Colombo. Permission for data collection was obtained from the Director of LRH and the Consultant paediatrician. Informed verbal consent was obtained from mothers before interviewing them. Refusal to participate was respected. Data was analysed using SPSS version 14. Frequencies were calculated for quantitative data. Associations between feeding practices and selected socio-demographic characteristics were analysed using Chi square test.

\section{Results}

Three hundred study units were collected serially according to inclusion and exclusion criteria. with a $100 \%$ response rate. Of them 5 were excluded from the analysis due to lack of CHDR $(n=1)$, could not read the CHDR yet $(n=2)$ and could not read / illiterate $(n=2)$.

The age range of the children was 6-24 months with a mean of $13.6 \pm 5.3$ months and $49 \%$ were males. Mean maternal age was $28.9 \pm 5.2$ years, the youngest being 18 years. Majority (81\%) belonged to Sinhala ethnic group and 52\% declared that the current hospital admission was their first. Nearly $37 \%$ reported their gross monthly income to be between Rs. $10,000 /=$ and $20,000 /=$ while $25 \%$ had an income of Rs. $20,000 /=$ to Rs. $40,000 /=$.

Socio-demographic factors of the sample are shown in Table 1.
Table 1: Socio-demographic factors of sample

\begin{tabular}{|l|c|}
\hline \multicolumn{1}{|c|}{ Socio-demographic factor } & No (\%) \\
\hline Ethnicity & $239(81)$ \\
Sinhala & $21(07)$ \\
Tamil & $35(12)$ \\
Muslim & \\
\hline No. of children in the family & $164(56)$ \\
One child & $96(33)$ \\
Two children & $35(12)$ \\
More than two children & \\
\hline Maternal employment status & $256(87)$ \\
Housewife & $39(13)$ \\
Employed & $81(28)$ \\
\hline Maternal educational level & \\
Up to secondary & $104(35)$ \\
Passed GCE O/L & $110(37)$ \\
GCE A/L \& above & \\
\hline Age starting complementary feeding & $04(02)$ \\
Before 4 months & $77(26)$ \\
4-6months & $212(72)$ \\
\hline After 6 months
\end{tabular}

One fourth of mothers gave either biscuits or commercially available cereals as the initial complementary food. Nearly $50 \%$ continued breast feeding while another $30 \%$ gave both breast milk and formula milk to their young children. Adequacy of complementary feeding pattern is shown in Table 2.

Table 2: Adequacy of complementary feeding pattern $(n=295)$

\begin{tabular}{|l|c|}
\hline \multicolumn{1}{|c|}{$\begin{array}{c}\text { Interviewers comment on } \\
\text { complementary feeding }\end{array}$} & No. (\%) \\
\hline Satisfactory & $142(48)$ \\
\hline $\begin{array}{l}\text { Satisfactory in frequency but not in } \\
\text { quality }\end{array}$ & $51(17)$ \\
\hline $\begin{array}{l}\text { Satisfactory in quality but not in } \\
\text { frequency/quantity }\end{array}$ & $25(09)$ \\
\hline Unsatisfactory & $77(26)$ \\
\hline
\end{tabular}

For the question on information sources that mothers have used with regard to complementary feeding, $28 \%$ indicated Public Health Midwife (PHM) as the sole information source and another $8 \%$ the CHDR. Moreover, 49\% stated family, mass media and PHM while $41 \%$ used the CHDR in addition to family and mass media. Of the mothers $44 \%$ admitted to reading the CHDR completely while another $54 \%$ have read it partially. We inquired on approximate time that mothers started reading CHDR. Nearly half (45\%) reported to reading $\mathrm{CHDR}$ around the birth of the child and $25 \%$ around the first month. Nearly $50 \%$ of them have read the CHDR because PHM has asked them. Basically there are 7 major parts of the CHDR namely, neonatal health record with length and weight graph, immunization record, vision and hearing testing, developmental milestones, care for 
the newborn, infant \& young child feeding, measuring psychosocial \& cognitive development, activities for child's psychosocial \& cognitive development. We asked whether mothers were able to read these sections completely, partly or not at all. The results are shown in Table 3.

Table 3: Distribution on extent of reading of CHDR by mothers

\begin{tabular}{|l|l|c|c|c|}
\hline & \multicolumn{1}{|c|}{ Section } & $\begin{array}{c}\text { Completely read } \\
\text { No. }(\%)\end{array}$ & $\begin{array}{c}\text { Partly read } \\
\text { No. }(\%)\end{array}$ & $\begin{array}{c}\text { Never read } \\
\text { No. }(\%)\end{array}$ \\
\hline 1 & CHDR* & $131(44.4)$ & $159(53.9)$ & \\
\hline 2 & Neonatal health record with length and weight graph & $216(73.2)$ & $53(18.0)$ & $26(08.8)$ \\
\hline 3 & Immunization record & $202(68.5)$ & $62(21.0)$ & $31(10.5)$ \\
\hline 4 & Vision and hearing & $203(68.8)$ & $70(23.7)$ & $22(07.5)$ \\
\hline 5 & Developmental milestones & $222(75.3)$ & $49(16.6)$ & $24(08.1)$ \\
\hline 6 & Care for the newborn & $205(69.5)$ & $60(20.3)$ & $30(10.2)$ \\
\hline 7 & Infant \& young child feeding & $179(60.8)$ & $95(32.2)$ & $17(05.8)$ \\
\hline 8 & Psychosocial \& cognitive development & $172(58.3)$ & $75(25.4)$ & $46(16.3)$ \\
\hline
\end{tabular}

* missing $=5 \quad{ }^{\$}$ missing $=4$

This shows $61 \%$ had read the section on IYCF completely while nearly $6 \%$ had never read it. When mothers were asked to spell out the reasons for reading the CHDR, more than three fourths have stated to gain new knowledge. Only 60\% knew about the colour zones in weight graph. As the reasons for not reading the CHDR-feeding section completely; $53 \%(n, 34)$ said lack of time while $6.3 \%$ stated difficulties in understanding and not reader friendly. With regard to overall impression of CHDR; $60 \%$ stated "good", $15 \%$ said "some parts difficult to understand" while $12 \%$ said "too many details \& no time to read".
Selected maternal socio-demographic factors were explored with reading of "feeding instructions" in the CHDR. Mothers with higher educational level read the "feeding instructions of CHDR" compared to mothers with lower educational levels. The difference was statistically significant. Reading IYCF instructions was not associated with maternal employment status $(p=0.2)$, maternal age group $(\mathrm{p}=0.9)$, monthly income level $(\mathrm{p}=0.6)$.

Complementary feeding practices regrouped as "Satisfactory" and "Not Satisfactory" (as per dietary history) were analysed with selected maternal factors (Table 4).

Table 4: Association between young child feeding pattern and selected family factors

\begin{tabular}{|c|c|c|c|c|}
\hline & $\begin{array}{c}\text { Satisfactory feeding } \\
\text { practices }(\%)\end{array}$ & $\begin{array}{c}\text { Unsatisfactory feeding } \\
\text { practices }(\%)\end{array}$ & Total & P value \\
\hline $\begin{array}{l}\text { No. of children in the family* } \\
\text { One child } \\
\text { Two children } \\
\text { More than two children }\end{array}$ & $\begin{array}{l}82(58) \\
45(32) \\
14(10)\end{array}$ & $\begin{array}{l}82(54) \\
51(34) \\
18(12)\end{array}$ & $\begin{array}{l}164(56) \\
96(33) \\
32(11)\end{array}$ & $\mathrm{P}=0.6$ \\
\hline $\begin{array}{l}\text { Maternal employment status } \\
\text { Housewife } \\
\text { Employed }\end{array}$ & $\begin{array}{l}119(84) \\
23(16) \\
\end{array}$ & $\begin{array}{c}137(89.5) \\
16(10.5) \\
\end{array}$ & $\begin{array}{c}256(87) \\
39(13) \\
\end{array}$ & $\mathrm{P}=0.7$ \\
\hline $\begin{array}{l}\text { Maternal age groups } \\
\text { Less than } 25 \text { years } \\
25 \text { years \& more }\end{array}$ & $\begin{array}{c}33(23) \\
109(77)\end{array}$ & $\begin{array}{l}44(29) \\
109(71)\end{array}$ & $\begin{array}{c}77(26) \\
218(74)\end{array}$ & $\mathrm{P}=0.3$ \\
\hline $\begin{array}{l}\text { Maternal educational level } \\
\text { GCE O/L \& above } \\
\text { Below GCE O/L }\end{array}$ & $\begin{array}{c}105(74.5) \\
36(25.5) \\
\end{array}$ & $\begin{array}{l}108(71) \\
45(29)\end{array}$ & $\begin{array}{l}213(72) \\
81(28) \\
\end{array}$ & $\mathrm{P}=0.6$ \\
\hline $\begin{array}{l}\text { Family Income per month } \\
=\text { or }<\text { Rs. } 20,000 \\
>\text { Rs. } 20,000\end{array}$ & $\begin{array}{l}101(71) \\
41(29)\end{array}$ & $\begin{array}{l}97(63) \\
56(37)\end{array}$ & $\begin{array}{l}198(67) \\
97(33)\end{array}$ & $\mathrm{P}=0.2$ \\
\hline $\begin{array}{l}\text { Maternal reading of IYCF } \\
\text { section in CHDR } \\
\text { Feeding part- read completely } \\
\text { Feeding part partially read or } \\
\text { never read }\end{array}$ & $\begin{array}{l}124(87) \\
18(13)\end{array}$ & $\begin{array}{l}115(75) \\
38(25)\end{array}$ & $\begin{array}{l}239(81) \\
56(19)\end{array}$ & $\mathrm{P}=0.006$ \\
\hline
\end{tabular}


Univariate analysis shows that satisfactory complementary feeding practices were neither associated with number of children in the family $(p=0.7)$, maternal employment status $(p=0.2)$, maternal age $(p=0.5)$ maternal educational level $(p=0.6)$, nor average monthly income $(p=0.2)$. Mothers who read the CHDR feeding instructions were having satisfactory IYCF practices $(p=0.01)$. This was further confirmed by the multivariate analysis with adjusted Odds ratio of 2.4 (95\% CI: 1.34.5). It means odds of having satisfactory IYCF practices among mothers who read IYCF part completely was 2.4 times greater than those who had read IYCF instructions partially or never read.

Of the mothers $95 \%$ knew about proper duration of exclusive breast feeding for 6 months and $86 \%$ said that the child should be given solid food by $8-9$ months of age. Two hundred and sixty one mothers $(88.5 \%)$ knew that it is better to introduce one food item at a time during complementary feeding. One fifth of mothers thought that it is good to start complementary feeding with commercially prepared cereals. Similarly $16 \%$ thought biscuits / baby rusks are better than rice while $47 \%$ think that it is not suitable to add meat or fish until the baby is $9-10$ months old. Of mothers $16 \%$ think apples and grapes are better compared to bananas and papayas when it comes to fruits. It is interesting that still 74 mothers $(25.1 \%)$ believe that offering rice during night is bad. One fifth of respondents answered affirmatively for the question on reducing meal frequency during illness while 14 (4.8\%) did not know the answer.

Regarding knowledge on IYCF, the range of marks was 0 to 15 with a mean of 11.4 (SD, 2.31). Nearly $30 \%$ scored less than 10 marks and 12 (4.4\%) mothers scored highest score of 15 marks. Since the frequency distribution showed skewed distribution, non parametric tests were used to measure differences between groups.

Maternal knowledge score was significantly higher among mothers with higher educational level and those who had read the CHDR IYCF instructions $(\mathrm{p}<0.05)$. However, maternal knowledge score was not associated with maternal age $(p=0.2)$, maternal employment status $(\mathrm{p}=0.2)$, prior hospital admissions $(0.3)$ or average monthly income of the family $(\mathrm{p}=0.7)($ Table 5).

Table 5: Maternal knowledge score by maternal \& family factors

\begin{tabular}{|l|c|c|}
\hline & Mean knowledge score (SD) & $\begin{array}{c}\text { M-W U test } \\
\text { P value }\end{array}$ \\
\hline $\begin{array}{l}\text { No. of children in the family* } \\
\text { One child } \\
\text { Two children }\end{array}$ & $11.4(2.4)$ & \\
More than two children & $11.6(2.0)$ & $\mathrm{P}=0.7$ \\
\hline Maternal employment status & $10.9(3.2)$ & $\mathrm{P}=0.2$ \\
Housewife & $11.4(2.3)$ & \\
Employed & $11.6(2.4)$ & $\mathrm{P}=0.001$ \\
\hline Maternal educational level & & \\
Below GCE O/L & $10.5(2.3)$ & $\mathrm{P}=0.2$ \\
Pass GCE O/L \& above & $11.8(2.2)$ & \\
\hline Maternal age groups & & $\mathrm{P}=0.7$ \\
Less than 25years & $11.1(2.3)$ & \\
25 years \& more & $11.5(2.0)$ & $\mathrm{P}=0.3$ \\
\hline Family Income per month & & \\
= or Rs.20,000 & $11.5(2.9)$ & \\
$>$ Rs.20,000 & $11.4(2.1)$ & $\mathrm{P}=0.001$ \\
\hline Number of previous hospital admissions & $11.6(2.1)$ & \\
None & $11.3(2.2)$ & \\
Once or more & $11.7(2.0)$ & \\
\hline Maternal reading of IYC feeding part in CHDR & $10.3(2.8)$ & \\
Feeding part- read completely & & \\
Feeding part partially read or never read & & \\
\hline
\end{tabular}

\section{Discussion}

In summary, mothers included in the sample had a generally acceptable level of IYCF knowledge and usage of CHDR as an information source. Since this study was restricted to a hospital it may not be advisable to generalise the findings.

Use of an interviewer administered questionnaire facilitated inclusion of all eligible mothers despite 
their education or literacy levels. Two trained registrars in paediatrics administered the questionnaire minimizing interviewer bias. However usage of 24 hour dietary recall during the day that child was last well could have introduced a recall bias. Some children would have been admitted to the ward after 1 or 2 days of illness while some would have been admitted after several days of illness. Child's diet was categorized as satisfactory or otherwise based on 24 hour dietary recall. It could have introduced a bias due to subjective interpretation of amount, consistency, quality and frequency of meals.

Almost all mothers (98\%) have read the CHDR completely or partially. Higher maternal educational level with nearly three fourths achieving education levels above GCE O/L in this sample could have facilitated reading CHDR. In addition, nearly half of the mothers declared that the current hospital admission was their second or third which can influence the usage of CHDR. Mothers are usually advised by doctors and nurses in wards about the importance of reading CHDR. These best practices should continue to be promoted by all health staff in institutions as well as the field health staff and general practitioners. It is important to emphasize that although 98\% admitted reading the CHDR, further analysis showed that there are deficiencies in comprehending some important sections like health record, immunization record and psychosocial development.

According to breast feeding policy, a child should be exclusively breast fed until completing 6 months of age. In the present sample, nearly $95 \%$ knew about correct duration of exclusive breast feeding while $72 \%$ had started complementary feeding after 6 months. Approximately 28\% have started complementary feeding before recommended 6 months replicating previous findings ${ }^{1,7,8}$. One reason may be that $15 \%$ of mothers were employed and they may have to return to work after maternity leave? However, $80 \%$ of mothers continued to breast feed with or without formula milk.

Undernutrition is a major problem among preschool children in Sri Lanka. Quality and quantity of complementary feeding has been highlighted as the main contributory factor for this nutrition problem ${ }^{8,10}$. Maternal education has been identified as a key factor in improving child nutrition ${ }^{10,11}$. However, in this study we failed to identify significant association between satisfactory feeding practices and maternal educational level.

Reading the CHDR has supported mothers on establishing satisfactory feeding (Table 4) stressing the importance of improving the CHDR in reader friendliness. It will facilitate reading as some mothers stated about difficulty in reading, comprehending and too many details. Reading CHDR was associated with higher maternal education level. The messages can be delivered in short, simple, specific and attractive manner using different colour codes according to sections to increase the reader friendliness and to facilitate reading by less educated mothers.

PHM has been identified as a source of information by $78 \%$ of mothers which has been showed in other studies $^{7,8}$. It is significant to note that still some misconceptions about feeding exist such as delay in adding animal protein till 9-10 months, offering meals during night time and feeding during illness. The above findings emphasize the need of educating mothers on specific IYCF instructions where the knowledge gaps prevail.

\section{Conclusions and recommendations}

- Mothers included in this study sample had a generally acceptable level of knowledge with regard to IYCF and satisfactory level of usage of CHDR as an information source.

- Complementary feeding practices were not satisfactory in majority of the sample. Despite limitations in reader friendliness, majority had used CHDR as information sources and reading CHDR has a significant impact on higher maternal IYCF knowledge and better IYCF practices.

- Health authorities need to improve the reader friendliness of the CHDR as an information source to improve their IYCF practices.

\section{Acknowledgements}

The authors gratefully appreciate the support given by the Director, Lady Ridgway Children's Hospital, Colombo and by all mothers and children who participated in the study.

\section{References}

1. DCS. Sri Lanka Demographic \& health Survey. Department of Census \& Statistics in collaboration with Ministry of Health; 2006-7.

2. WHO. Complementary feeding of young children in developing countries: A review of current scientific knowledge. In. Geneva: World Health Organization 1998. 
3. Perera $\mathrm{P}$, Fernando $\mathrm{M}$, Warnakulasuria $\mathrm{T}$, Ranathunga N. Feeding practices among children attending child welfare clinics in Ragama $\mathrm{MOH}$ area: a descriptive cross-sectional study. International Breastfeeding Journal 2011; 6(18). Available from:

http:/www.ncbi.nlm.nih.gov/pmc/articles/PMC3 $248855 /$

4. Senarath U, Dibley M. Complementary feeding practices in South Asia: analyses of recent national survey data by the South Asia Infant Feeding Research Network. Maternal \& Child Nutrition 2012; 8 (Suppl. 1:5-10). Available from:

http://onlinelibrary.wiley.com/doi/10.1111/j.174 $\underline{0-8709.2011 .00371 . x / f u l l}$

5. WHO. 55th World Health Assembly: WHA 55.25 Infant \& Young child Nutrition. In. Geneva: World Health Organization; 2002.

6. Ministry of Health. Child Health Development Record. Family Health Bureau.2007

7. Dhammika B, Gunawardena N. Knowledge, practices and concerns regarding exclusive breastfeeding for six months among mothers of infants in a suburban setting in Sri Lanka. Sri Lanka Journal of Child Health 2012, 41(1):9-14. Available from:

http://www.sljol.info/index.php/SLJCH/article/vi ew/4130

http://dx.doi.org/10.4038/sljch.v41i1.4130
8. Sri Lanka Complementary Feeding Study. Factors Associated with Complementary Feeding in Sri Lanka. In.: Ministry of Healthcare \& Nutrition in collaboration with UNICEF; 2008.

9. Agampodi S, Agampodi T, Piyaseeli U. Breastfeeding practices in a public health field practice area in Sri Lanka: a survival analysis. International Breastfeeding Journal 2007, 2(13). Available from:

http://www.internationalbreastfeedingjournal.co $\underline{\mathrm{m} / \text { content } / 2 / 1 / 13}$

10. Senarath U, Godakandage SSP, Jayawickrama H, Siriwardena I, Dibley MJ. Determinants of inappropriate complementary feeding practices in young children in Sri Lanka: secondary data analysis of Demographic and Health Survey 2006-2007. Maternal \& Child Nutrition 2012, 8:60-77. Available from: http://dx.doi.org/10.1111/j.17408709.2011.0037 $\underline{5 . x}$

11. Imdad A, Yakoob MY, Bhutta ZA. Impact of maternal education about complementary feeding and provision of complementary foods on child growth in developing countries. BMC Public Health 2011, 11 (Suppl 3):S25. Available from:

http://www.ncbi.nlm.nih.gov/pubmed/21501443 http://dx.doi.org/10.1186/1471-2458-11-S3-S25 